\title{
BIOCHEMICAL COMPOSITION OF VEGETABLE RAW MATERIALS AND THE IMPACT OF DOSAGE ON THE PROPERTIES OF PROCESSED CHEESE
}

\author{
Dinara Tlevlessova ${ }^{1}$, Mariam Alimardanova ${ }^{2}$, Assemay Kazhymurat ${ }^{3}$ \\ ${ }^{1}$ Department of "Mechanization and Automation of Manufacturing Processes", Almaty Technological University, Almaty, Republic of \\ Kazakhstan \\ tlevlessova@gmail.com \\ ORCID: https://orcid.org/0000-0002-5084-6587 \\ ${ }^{2}$ Department of Food Technology, Almaty Technological University, Almaty, Republic of Kazakhstan \\ ORCID: https://orcid.org/0000-0003-4861-7862 \\ ${ }^{3}$ Department of Safety and Quality of Food Product, Almaty Technological University, Almaty, Republic of Kazakhstan \\ ORCID: https://orcid.org/0000-0001-5359-5528
}

\begin{tabular}{l} 
A RT I C L E IN F O \\
\hline Article history: \\
Received date 23.03.2021 \\
Accepted date 27.04.2021 \\
Published date 30.04.2021 \\
Section: \\
Food production \\
D O I
\end{tabular}

$10.21303 / 2313-8416.2021 .001794$

KEYWORDS

Allium odorum

processed cheese

mineral composition

\section{ABSTRACT}

The object of research is the cream cheese, elaborated using vegetable raw materials. Investigated problem: This article provides information on the biochemical composition of leaves of A. odorum. The leaves of wild onions revealed a high content of vitamin C, macroand microelements and other biologically active substances, indicating high nutritional and vitamin value and prospects of these species for use as fillers in the dairy industry.

The main scientific results: A. odorum refers to green vegetable plants, rich enough variety of biologically active substances. Unlike other perennial species of onion, A. odorum characterized by low protein content (1.1-1.8 \%) and a relatively high solids content (in the bulb up to $17 \%$ in the leaves $10.5-11.3 \%$ ), sugars (10.9-12.1\%).

The area of practical use of the research results: There will be researched a possibility of Allium odorum usage as an addition for new processed cheese production and an influence of plant raw material dosage on structure of the processed cheese.

Innovative technological product: Products developed within the framework of integrated technology are distinguished by high quality, nutritional value, safety, preservation of special nutrients: essential amino acids, fatty acids, omega 6 vitamins, bioflavonoids. The recipe solutions about the elements of innovative complex technologies are reflected in the patents that are included in the Derwent database.

Scope of the innovative technological product: Plant raw materials can be used both in pharmaceuticals to isolate saponins and to increase the nutritional and biological value of food products. In this article, we considered it in the production of processed cheeses, but it can be used as a seasoning for dishes. Content of inulin, quercetin, saponins, vitamin K, selenium, etc. makes this source very promising, it also has fungicidal properties and allows you to increase the shelf life of food products.

(C) The Author(s) 2021. This is an open access article under the Creative Commons CC BY license

\section{Introduction}

The use of wild plants as medicinal raw materials and food additives prophylactic administration is becoming increasingly important. Species of the genus Allium L. widely used as edible and medicinal plants.

In general, the flora is very rich Central Asian bows, they participate in the composition of vegetation over large areas. No wonder one of the names of the Tien Shan - Cun-Linh, which in Chinese means "Onion Mountain”. In the East Kazakhstan region was named payon Kolbinskim, from the word "bulb" - wild garlic (Allium victoriale L). Many wild onions have long been known as food plants. In the food used by the bulb and leaves (pen) any edible onion (rarely - only the bulbs or leaves, sometimes - flower arrows, and inflorescence) [1].

Due to its chemical composition leaves A. odorum little gross and retain good flavor and tenderness throughout the growing season and can be used until late fall. The leaves also contain large amounts of vitamins $\mathrm{A}$ and $\mathrm{C}$ and minerals (potassium, phosphorus, iron, manganese, zinc, copper, molybdenum, cobalt). Like garlic, onions, this contains allicin, which activates vitamin B1. Compared with other types of long-term onions it leaves most rich in essential oils. A. odorum, like 
other types of onions, contains many volatile production, kill bacteria. The large number of biologically active substances in the bow increases the body's resistance to various infectious diseases. According to the USDA SR-23, USDA National Nutrient Database for Standard Reference Allium family potrebelenie cover the recommended daily vitamin $\mathrm{K}$ at $177 \%$.

Vitamin $\mathrm{K}$ is necessary as a means to increase blood clotting, and more precisely - for the formation of prothrombin, which usually occurs in the liver when it is healthy. Micro-organisms in our body produce enough of this vitamin, but with abnormal liver function, or prolonged use of drugs, especially sulfa drugs or salicylic, this is not happening. Vitamin K and plays an important role in bone formation and repair, allows synthesis of osteocalcin - bone protein, lint, which crystallized calcium. It contributes to the prevention of osteoporosis, is involved in the regulation of redox processes in the body.

The daily requirement for vitamin $\mathrm{K}$ adults is not certain, it is approximately 60-140 micrograms. The need for vitamin $\mathrm{K}$, i.e. that amount which is needed to prevent deficiency in normal conditions, the $1 \mathrm{ug}$ per kilogram body weight per day. With a weight of $60 \mathrm{~kg}$ person needs $60 \mathrm{mcg}$ of vitamin K per day. Typical diet contains from 300 to 500 micrograms of vitamin K per day [2].

\section{1. The object of research}

The object of research is the cream cheese, elaborated using vegetable raw materials.

\section{2. Description of the problem}

Processed cheese is a dairy product manufactured by adding suitable emulsifying salts (e.g. sodium salts of phosphates, polyphosphates and citrates) to natural cheese in the presence of heat and constant agitation. Other optional dairy (butter, skim milk powder, whey powder, coprecipitates, casein, caseinates, rework - processed cheese that is reused as a blend ingredient in later batches of processed cheese product, etc.) and non-dairy ingredients (water, vegetables and spices, meats, flavourings, colourings, salt, hydrocolloids, preservatives, etc.) can be added into the mixture. Some of the dairy and non-dairy ingredients could contain various polysaccharides, disaccharides (especially lactose or saccharose) and monosaccharides (e.g. glucose, galactose, etc.) [3]

A growing body of data indicates that there is considerable potential for utilization of natural antimicrobials in food, especially application to fresh fruits and vegetables, for their oxidative degradation of lipids and improvement of the quality and nutritional value of food, in addition to their strong antifungal effects. EOs derived from spices and plants have antimicrobial activity against L. monocytogenes, Salmonella typhimurium, Escherichia coli O157:H7, Shigella dysenteriae, Bacillus cereusand Staphylococcus aureus at levels between 0.2 and $10 \mu \mathrm{ml}^{-1}$ [4]

Among these, extensive studies carried out on garlic (Allium sativum L.) have reported the presence of two main classes of antioxidant components, namely flavonoids [5] and sulfur-containing compounds (diallyl sulfide, trisulfide and allyl-cysteine) [6].

Medicinal plants have been used by all civilization as a source of medicines since ancient times. In the recent time, there has been growing interest in exploiting the biological activities of different ayurvedic medicinal herbs, due to their natural origin, cost effectiveness and lesser side effects.

Interest in medicinal plants as a re-emerging health aid also has been fuelled by the rising costs of prescription drugs in the maintenance of personal health and well-being, and the bioprospecting of new plant-derived drugs [7].

These are likely to play an important role in the widely demonstrated biological effects of garlic, which include antitumor [8], antioxidant [9] and immunomodulatory [10] effects.

\section{3. Suggested solution to the problem}

As was shown, the substances included in the onion, inhibits the growth of tumors and microbial cells, reduce the risk of cancer, capture free radicals and protect the human cardiovascular diseases, which is attributed to the presence of sulfur compounds and flavonoids.

The aim of this research is to develop a new type of processed cheese, increased biological value of processed cheeses, to study the influence of dose and type of vegetable raw materials on the texture of processed cheese. 


\section{Material and Methods}

\section{1. Research model}

According to this scheme, a vegetable filler was selected, the possibility of adding vegetable raw materials in processed and fresh form and the effect on the taste of processed cheese was investigated (Fig. 1).

\begin{tabular}{|l}
\hline $\begin{array}{c}\text { mathematical modeling recipe } \\
\text { calculation of balance components } \\
\text { choice of vegetable raw materials }\end{array}$ \\
\hline chemical composition, biological value prevalence, availability \\
\hline by thermal treatment \\
\hline Study of the method of incorporation into the processed cheese \\
during melting \\
during cooling \\
\hline Study of the effect of dose on plant raw material consistency processed cheese \\
different doses \\
\hline
\end{tabular}

Fig. 1. Research algorithm

\subsection{Data analysis}

Research Methods: Evaluation of organoleptic properties to 30-point scale (including taste and smell - 15 points, consistency - 10 points, color and appearance -5 points).

Analyzing the organoleptic indicators presented in the diagram (Fig. 2), we can conclude that the optimal dose of herbal raw materials in the form of a powder is $5 \%$ (sample number 3 ), for fresh plant materials $7 \%$ (sample number 6 ) to obtain processed cheese with better touch performance.

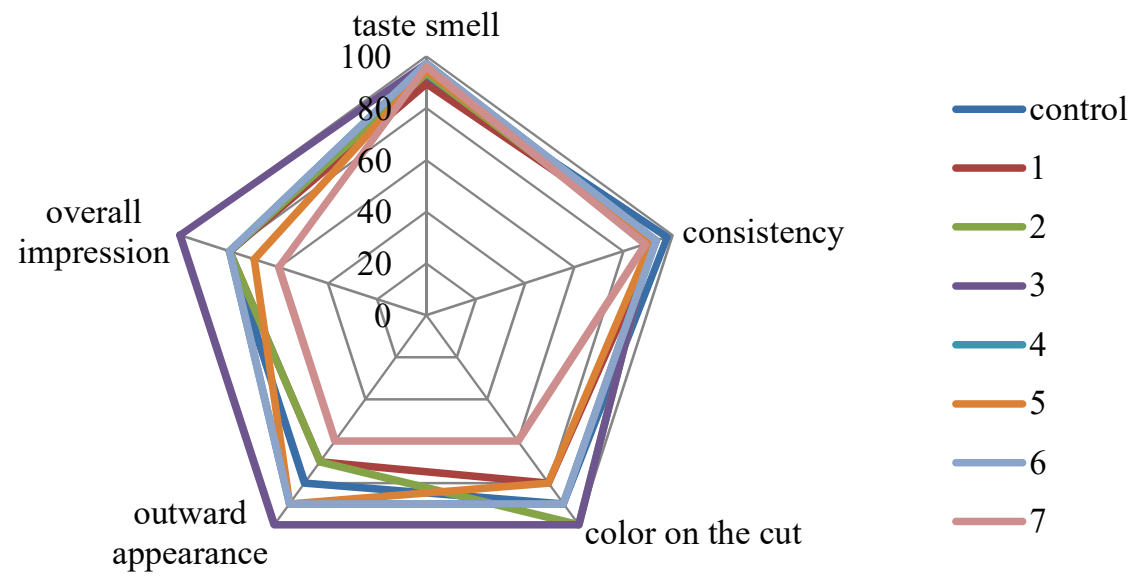

Fig. 2. The organoleptic indicators developed processed cheese (dose variation vegetable raw materials) in comparison with the control

The object of study is a plant $A$. odorum. of the regional flora and RK prepared powders of air-dried leaves of $A$. odorum. Research Methods: The total flavonoid content was determined by the method of quantitative determination of total flavonoids by UV spectrophotometry in terms of quercetin and luteolin-7-glycoside (tsinarozid) developed [11]

Assessment of the quality of the pen A. odorum invited to conduct on the content of flavonoids. The technique of quantitative determination of the amount of flavonoids by UV spectropho- 
tometry based on quercetin. The conditions for the extraction of flavonoids from raw succession of ethanol $96 \%, 70 \%$ and $40 \%$ concentrations. The ratio of total feed and extractant of 1:100, while extracting three times in a boiling water bath for 90 minutes.

To calculate the total flavonoid quercetin in terms of optical density of the absorbance measured at its $A$. odorum alcohol extraction after hydrolysis at $370 \mathrm{~nm}$. Calculation of total flavonoids was performed using the optical density of the standard sample solution quercetin. The relative error of the proposed method $-1.54 \%$. The content of flavonoids in the aerial part of the A. odorum pen is $1.351 \pm 0.021 \%$.

It is found that a maximum UV absorbance spectrum of the intrinsic absorption of the alcohol extraction after hydrolysis pen $A$. odorum coincides with the maximum UV absorbance spectrum of the standard solution state tion quercetin sample (Fig. 3).

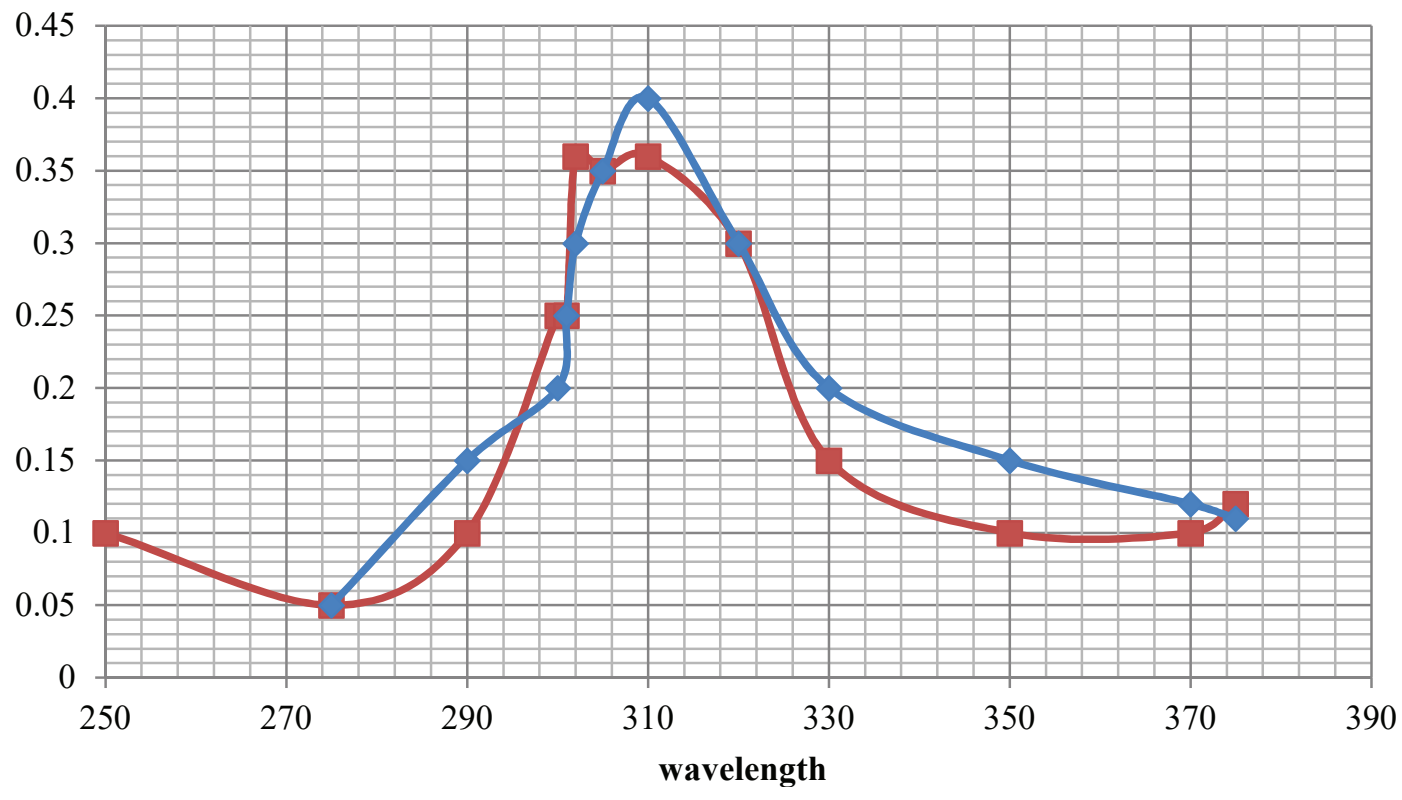

Fig. 3. The absorbance of the extract compared with A. odorum GSO quercetin

Method of producing alcoholic extract pen A. odorum (extraction method with successive changes of $96 \%$ ethanol, $70 \%$ and $40 \%$ concentrations). Grass cuff accurately weighed about $1.0 \mathrm{~g}$ was placed in a flask with ground joint capacity of $150 \mathrm{ml}, 30 \mathrm{ml}$ of $96 \%$ ethanol, and the flask was attached to a reflux condenser and heated on a steam bath for 30 minutes. The flask was then cooled to room temperature and the flask contents were filtered through filter paper into a volumetric flask of $100 \mathrm{ml}$. Then, the above extraction process was repeated successively $70 \%$ and $40 \%$ ethanol. Extract was filtered through the same filter to the same flask. The filtrate was adjusted to the mark with $96 \%$ alcohol

Method for quantitative determination of total flavonoids calculated as quercetin. $10 \mathrm{ml}$ of alcoholic extract obtained from the raw $A$. odorum evaporated on a water bath, the residue was dried in an oven at $110{ }^{\circ} \mathrm{C}$ for 10 minutes, then dissolved in $10 \mathrm{ml}$ of $10 \%$ sulfuric acid. Hydrolysis conducted in a flask connected to a reflux condenser under heating in a boiling water bath for 2 hours. Under these conditions, the hydrolysis of only 3-O-glycosides, 7-O-glycosides, as more resistant to hydrolysis undergo a more stringent conditions. The flask was then cooled to room temperature and its contents filtered through filter paper. The precipitate remaining on the filter, washed with purified water, and dissolved in $100 \mathrm{ml}$ of hot $96 \%$ ethanol.

An aliquot of the solution volume was adjusted to $10 \mathrm{ml}$ mark on the flask $25 \mathrm{ml}$ of $96 \%$ ethyl alcohol and the absorbance of the resulting solution in a spectrophotometer JENWEY 6705 UV/VIS wavelength range of $250-450 \mathrm{~nm}$ in a cuvette with a layer thickness of $10 \mathrm{~mm}$.

The content of total flavonoids based on the formula of quercetin were 1:

$$
X=\frac{A_{x} \times C_{s t} \times W \times 100}{A_{s t} \times C_{x} \times V_{a}},
$$


where $A_{x}$ - optical density of the sample solution; $C_{S t}$ - the concentration of the reference solution of quercetin; $W$-breeding, $\mathrm{ml} ; A_{s t}$ - absorbance of the reference solution of quercetin; $C_{x}-$ concentration of the test solution; $V_{a}$ - volume aliquots $\mathrm{ml}$.

\section{Results}

The results of statistical data processing parallel measurements shown showed that the content in flavonoids based on $A$. odorum quercetin was $9.4 \% \pm 0.02438 \%$, the error of a single determination at a confidence level of $98 \%$ was $1.77 \%$ (Tables 1, 2).

\section{Table 1}

Results of quantitative for Flavonoid Amount to A. odorum in terms of quercetin

\begin{tabular}{cccc}
\hline$\overline{\boldsymbol{X}}(\%)$ & $\left(\overline{\boldsymbol{X}}-\boldsymbol{X}_{\boldsymbol{i}}\right)$ & $\left(\overline{\boldsymbol{X}}-\boldsymbol{X}_{\boldsymbol{i}}\right)^{\mathbf{2}}$ & Metrological characteristics \\
\hline 1.311 & 0.040 & 0.00159 & $\bar{X}=1,351$ \\
1.357 & -0.006 & 0.00004 & $\sum\left(\bar{X}-X_{i}\right)^{2}=0.002$ \\
1.365 & -0.014 & 0.00020 & $S_{x}=\sqrt{\frac{\sum\left(\bar{X}-X_{i}\right)^{2}}{n(n-1)}=0.0081}$ \\
1.359 & -0.008 & 0.00007 & $\Delta X=S_{x} \cdot t_{x}=0.021$ \\
1.354 & -0.003 & 0.00001 & $\varepsilon=1.54$ \\
1.359 & -0.008 & 0.00007 &
\end{tabular}

Table 2

Results of quantitative determination of total flavonoids in melted cheese with $A$. odorum in terms of quercetin

\begin{tabular}{cccc}
\hline$\overline{\boldsymbol{X}}(\boldsymbol{\%})$ & $\left(\overline{\boldsymbol{X}}-\boldsymbol{X}_{\boldsymbol{i}}\right)$ & $\left(\overline{\boldsymbol{X}}-\boldsymbol{X}_{\boldsymbol{i}}\right)^{\mathbf{2}}$ & Metrological characteristics \\
\hline 0.241 & 0.000 & 0.00000 & $\bar{X}=0.241$ \\
0.237 & 0.004 & 0.00002 & $\sum\left(\bar{X}-X_{i}\right)^{2}=0.00006$ \\
0.243 & -0.002 & 0.00000 & $S_{x}=\sqrt{\frac{\sum\left(\bar{X}-X_{i}\right)^{2}}{n(n-1)}=0.0014}$ \\
0.247 & -0.006 & 0.00003 & $\Delta X=S_{x} \cdot t_{x}=0.04$ \\
0.239 & 0.002 & 0.00001 & $\varepsilon=1.571$ \\
0.2414 & 0.000 & 0.00000 &
\end{tabular}

\section{Discussion}

The literature has repeatedly had high antioxidant properties of long-term onions, caused by the presence of specific chemical forms of selenium, and high concentration of vitamin E, C and flavonoids [12, 13]. sides [14].

Many medicinal properties associated with the presence of bow therein steroid glyco-

The greatest number of steroidal glycosides contained in onions inflorescence: $A$. odorum $-2.51 \pm 0.14$.

The most important indicator of the practical value of wild onions as a food and medicinal plants is the content of ascorbic acid. The leaves of onions in period spring regrowth revealed: $31.36-149.76 \mathrm{mg} \%$ ascorbic acid; $31.20-187.20 \mathrm{mg} / \mathrm{kg}$ carotene; $11.68-21.31 \%$ protein based on dry substance For carotene content is relatively high accumulation of different A. odorum $-187.21 \mathrm{mg} / \mathrm{kg}$.

Fructans are typical prebiotics: -communication of these molecules is not split glucosidase intestine, and therefore they are not digested and reach the large intestine, where utilized by microorganisms [15]. Thus, fructans contribute to increasing the number of bifidobacteria and lactobacilli. T. R. Licht et al. experimental work on rats showed that a diet rich in inulin 
or oligofructose, increases microbial mass in the colon, decrease $\mathrm{pH}$ of the intestinal contents, increase in the number of lactobacilli and reduce coliform microorganisms amount [16].

Study limitation. The limitations of the study are that wild onions have a wide range of growth and, depending on the soil, climate and other factors, their composition changes. The difficulty is to calculate the dosage of plant materials in processed cheese, so that to cover the daily need for vitamin $\mathrm{K}$ and minerals. This onion is rich in selenium in its composition, has a small amount of inulin, phytoncides and polyphenols.

Prospects for further research. The prospects for further research are broad since we can use this raw material to obtain saponins. This onion is a good source of saponins. In the future, identify to which group they belong, but I assume that these are steroid saponins. In the medical periodicals in connection with the pandemic, there have appeared many works devoted to the study of plant raw materials. Many of them say that steroid saponins are used to combat covid, hence the conclusion that this resource is useful not only as an additive to food products but also as a source of saponins for pharmaceuticals. Also, work continues to study a more optimal way to add this plant raw material to dairy products. Study the nature of their interaction.

\section{Conclusion}

The possibility of using plant materials in the manufacture of processed cheese products. This gives the product a distinctive taste, helps ensure a good consistency and allows the product to acquire its original color.

However, the severity of these parameters depends on the type of plant material, the form of preparation of processing, the constituent components of the product, technological features of production and other factors.

From the above materials, it can be seen that the plant material has a moisture-binding ability to influence the texture and processed cheese according to a new recipe generated using Excel simulated packaging. So, it is possible to see that the presence of inulin in the structure of plant raw materials gives a shine to development, since our recipe for processed cheese and cheese, when added to a lot of elastic consistency, really affects the smell from the above, that the optimal dose of plant raw materials in powder is $5 \%$, for fresh vegetable raw materials $7 \%$.

\section{References}

[1] Shirshova, T. I., Beshlei, I. V., Matistov, N. V., Golubkina, N. A. (2011). Soderzhanie selena v kulturnykh i dikorastuschikh lukakh iz flory Respubliki Komi. Rastitelnye resursy, 47 (1), 112-118.

[2] Kasimova, E. Dietologi rasskazali, zachem nam tak nuzhen vitamin K. Available at: http://www.inmoment.ru/beauty/health-body/ vitamin-k.html

[3] Guinee, T. P., Caric, M., Kalab, M.; Fox, P. F., McSweeney, P. L. H., Cogan, T. P. (Eds.) (2004). Pasteurized processed cheese and substitute/imitation cheese products. Cheese: Chemistry, physics and microbiology. Major cheese groups, Vol. 2. London, New York: Elsevier Applied Science, 349-394. doi: http://doi.org/10.1016/s1874-558x(04)80052-6

[4] Burt, S. (2004). Essential oils: Their antibacterial properties and potential applications in foods - A review. International Journal of Food Microbiology, 94 (3), 223-253. doi: http://doi.org/10.1016/j.ijfoodmicro.2004.03.022

[5] Bozin, B., Mimica-Dukic, N., Samojlik, I., Goran, A., Igic, R. (2008). Phenolics as antioxidants in garlic (Allium sativum L., Alliaceae). Food Chemistry, 111 (4), 925-929. doi: http://doi.org/10.1016/j.foodchem.2008.04.071

[6] Sharma, V., Sharma, A., Kansal, L. (2010). The effect of oral administration of Allium sativum extracts on lead nitrate induced toxicity in male mice. Food and Chemical Toxicology, 48 (3), 928-936. doi: http://doi.org/10.1016/j.fct.2010.01.002

[7] Mukhtar, M., Arshad, M., Ahmad, M., Pomerantz, R. J., Wigdahl, B., Parveen, Z. (2008). Antiviral potentials of medicinal plants. Virus Research, 131 (2), 111-120. doi: http://doi.org/10.1016/j.virusres.2007.09.008

[8] Ejaz, S., Woong, L. C., Ejaz, A. (2003). Extract of garlic (Allium sativum) in cancer chemoprevention. Experimental oncology, 25, 93-97. Available at: http://exp-oncology.com.ua/wp/wp-content/uploads/magazine/274.pdf?upload=

[9] Omurtag, G. Z., Güranlioğlu, F. D., Şehirli, Ö., Arbak, S., Uslu, B., Gedik, N., Şener, G. (2005). Protective effect of aqueous garlic extract against naphthalene-induced oxidative stress in mice. Journal of Pharmacy and Pharmacology, 57 (5), $623-630$. doi: http://doi.org/10.1211/0022357055939

[10] Bruck, R., Aeed, H., Brazovsky, E., Noor, T., Hershkoviz, R. (2005). Allicin, the active component of garlic, prevents immune-mediated, concanavalin A-induced hepatic injury in mice. Liver International, 25 (3), 613-621. doi: http://doi.org/10.1111/ j.1478-3231.2005.01050.x 
[11] Mitrofanova, I. Yu., Yanitskaya, A. V., Gukasova, V. V. (2014). The different technological factors' influence on the extraction efficiency of the flavonoids from Inula Britannica herb. Scientific reports of Belgorod State University. Series: Medicine. Pharmacy, 25 (4 (175)), 244-249.

[12] Alimardanova, M. K., Tlevlessova, D. A., Simov, Zh., Dimitrov, D., Matibayeva, A. I. (2015). Incorporating Allium odorum as Vegetable Ingredient of Processed Cheeses. Research Journal of Pharmaceutical, Biological and Chemical Science, 6 (3), 330-338.

[13] Tuhvatullina, L. A. (2007). Produktivnost i soderzhanie askorbinovoi kisloty v vidah roda Allium L. v uslovijah introdukcii. Teoreticheskie i prikladnye aspekty introdukcii rastenii kak perspektivnogo napravleniia razvitiia nauki i narodnogo hoziaistva, 2, 161-164.

[14] Nuutila, A., Puupponen-Pimiä, R., Aarni, M., Oksman-Caldentey, K.-M. (2003). Comparison of antioxidant activities of onion and garlic extracts by Inhibition of lipid peroxidation and radical scavenging activity. Food Chemistry, 81, 485-493. doi: http:// doi.org/10.1016/s0308-8146(02)00476-4

[15] Licht, T. R., Hansen, M., Poulsen, M., Dragsted, L. O. (2006). Dietary carbohydrate source influences molecular fingerprints of the rat faecal microbiota. BMC Microbiol, 30 (6), 98. doi: http://doi.org/10.1186/1471-2180-6-98

[16] Su, P., Henriksson, A., Mitchell, H. (2007). Selected prebiotics support the growth of probiotic mono-cultures in vitro. Anaerobe, 13 (3-4), 134-139. doi: http://doi.org/10.1016/j.anaerobe.2007.04.007 